\title{
Analysis of actinic flux profiles measured from an ozonesonde balloon
}

\author{
P. Wang, M. Allaart, W. H. Knap, and P. Stammes \\ Royal Netherlands Meteorological Institute (KNMI), De Bilt, the Netherlands \\ Correspondence to: P. Wang (ping.wang@knmi.nl)
}

Received: 22 October 2014 - Published in Atmos. Chem. Phys. Discuss.: 10 December 2014

Revised: 31 March 2015 - Accepted: 31 March 2015 - Published: 21 April 2015

\begin{abstract}
A green light sensor has been developed at KNMI to measure actinic flux profiles using an ozonesonde balloon. In total, 63 launches with ascending and descending profiles were performed between 2006 and 2010. The measured uncalibrated actinic flux profiles are analysed using the Doubling-Adding KNMI (DAK) radiative transfer model. Values of the cloud optical thickness (COT) along the flight track were taken from the Spinning Enhanced Visible and Infrared Imager (SEVIRI) Cloud Physical Properties (CPP) product. The impact of clouds on the actinic flux profile is evaluated on the basis of the cloud modification factor (CMF) at the cloud top and cloud base, which is the ratio between the actinic fluxes for cloudy and clear-sky scenes. The impact of clouds on the actinic flux is clearly detected: the largest enhancement occurs at the cloud top due to multiple scattering. The actinic flux decreases almost linearly from cloud top to cloud base. Above the cloud top the actinic flux also increases compared to clear-sky scenes. We find that clouds can increase the actinic flux to 2.3 times the clear-sky value at cloud top and decrease it to about 0.05 at cloud base. The relationship between CMF and COT agrees well with DAK simulations, except for a few outliers. Good agreement is found between the DAK-simulated actinic flux profiles and the observations for single-layer clouds in fully overcast scenes. The instrument is suitable for operational balloon measurements because of its simplicity and low cost. It is worth further developing the instrument and launching it together with atmospheric chemistry composition sensors.
\end{abstract}

\section{Introduction}

Atmospheric trace gases such as ozone and nitrogen dioxide are involved in a series of chemical reactions driven by solar radiation at UV wavelengths (Crutzen and Zimmermann, 1991). Actinic flux (AF) - which is the integral of the radiance over all directions, i.e. $4 \pi$ solid angle - is relevant to the process of photodissociation. Clouds have a large impact on the actinic flux in the atmosphere and, consequently, on photodissociation rates (Calbó et al., 2005). Therefore, the actinic flux profile is important for the study of the change in concentration of chemically reactive components in the atmosphere and is preferably measured together with the atmospheric chemical composition. Such actinic flux profiles have been measured by means of balloons and aircrafts during several campaigns.

During the Atlantic Stratocumulus Experiment (ASTEX), tethered balloon soundings were performed on Santa Maria, Azores. Vilà-Guerau de Arellano et al. (1994) compared measured actinic flux profiles with simulations using a deltaEddington model. Excellent agreement was found for fully cloudy scenes. The authors reported that the actinic flux decreased from cloud top to cloud base. At cloud top the actinic flux was higher than the clear-sky actinic flux, while at cloud base the actinic flux was lower than the clear-sky values. In the First ISCCP Regional Experiment (FIRE III) Arctic Cloud Experiment actinic fluxes were measured above sea ice in May 1998. De Roode et al. (2001) found that the actinic flux profile within clouds is nearly constant with height, except in a shallow layer below cloud top where the actinic flux revealed a large increase. The authors attributed this feature to the bright surface of sea ice (high albedo). Actinic fluxes were measured on the ground and on an aircraft during the INSPECTRO campaign to study the effect 
of clouds on the spectral actinic flux in East Anglia, England, in 2003. Kylling et al. (2005) showed that the spectral actinic flux can be reproduced with a 1-D radiative transfer model for clear-sky and fully cloudy cases. They reported that the actinic flux (in the UV wavelength range) could be enhanced by as much as $60-100 \%$ above clouds and reduced by $55-65 \%$ below clouds, as compared to the clear-sky situation. Junkermann (1994) measured $\mathrm{J}\left(\mathrm{O}^{1} \mathrm{D}\right)$ actinic flux within and above stratiform clouds and above snow surfaces from a hang-glider with flight altitude of up to $1 \mathrm{~km}$ above ground. The actinic flux showed a very strong contribution of reflected or backscattered radiation within the planetary boundary layer. Palancar et al. (2011) reported extensive comparisons between aircraft-based measurements (between 0.1 and $11.9 \mathrm{~km}$ altitude) of actinic fluxes and Tropospheric Ultraviolet-Visible (TUV) model simulations. They found a good agreement between the measured and TUV clear-sky model actinic fluxes (integrated from 298 to $422 \mathrm{~nm}$ ). Including both cloudy and clear-sky conditions, the ratio of observed actinic flux to the TUV clear-sky model value was $1.1 \pm 0.3$. Furthermore, accurate spectral actinic flux measurements (280-420 $\mathrm{nm}$ ) between ground and $12 \mathrm{~km}$ altitude were made by Hofzumahaus et al. (2002) from an aircraft. Actinic flux profiles have also been measured by balloons in the stratosphere (Schiller et al., 1994) and in the troposphere and stratosphere (Kylling et al., 2003).

On the ground, UV monitoring stations usually measure spectral irradiances. The relation between the actinic flux and the irradiance has been studied in several papers (e.g. Madronich, 1987; van Weele et al., 1995; Kazadzis et al., 2000; McKenzie et al., 2001). In general, the actinic flux correlates well with the irradiance on the surface, but the relationship depends on wavelength, surface albedo, solar zenith angle, and cloud conditions.

Most actinic flux profiles presented in the literature were measured in the lower troposphere in the UV wavelength range. Actinic flux observations at green wavelengths (about $510 \mathrm{~nm}$ ) are more representative for photodissociation by visible light. In combination with ozone and $\mathrm{NO}_{2}$ observations, the actinic flux profile observations are useful to investigate the photostationary state relationship between $\mathrm{NO}$, $\mathrm{NO}_{2}$, and $\mathrm{O}_{3}$ in cloudy scenes in detail (Cantrell et al., 1993; Mannschreck et al., 2004). Knowledge of the chemical interrelationship between $\mathrm{O}_{3}$ and $\mathrm{NO}_{2}$ is important to better constrain their vertical profile in air quality models and in satellite retrievals of $\mathrm{O}_{3}$ and $\mathrm{NO}_{2}$. The actinic flux at $\mathrm{UV}$ wavelengths is more relevant to the photodissociation of $\mathrm{NO}_{2}$ and $\mathrm{O}_{3}$ than the actinic flux at visible wavelengths. However, good measurements and simulations of the actinic flux at visible wavelengths will give some confidence in our simulations at the UV wavelengths. It was intended to be a cheap, disposable instrument and not harmful to the environment. Therefore, we measured actinic flux profiles using a green light sensor attached to an ozonesonde. Another advantage of using an operational ozonesonde is the large altitude range (from surface up to $35 \mathrm{~km}$ ) and the regularity of launching. The aims of the actinic flux profile measurements are to evaluate the impact of clouds on the actinic flux profiles and to better constrain the $\mathrm{O}_{3}$ and $\mathrm{NO}_{2}$ chemical inter-relationship in atmospheric chemistry models.

The cloud modification factor (CMF) is often used in the analysis of cloud effects on UV radiation (e.g. Seckmeyer et al., 1996; Mayer et al., 1998; Schwander et al., 2002; Antón et al., 2012; Mateos et al., 2014). The cloud modification factor is the ratio between radiation under cloudy and clear-sky conditions. The radiation for clear-sky scenes is calculated using the same atmospheric states as for cloudy scenes. It has been demonstrated and explained that the surface CMF in the UV has a wavelength dependence (Seckmeyer et al., 1996; Crawford et al., 2003). The transmission of clouds alone does not have a significant wavelength dependence in the UV, but Rayleigh scattering does. According to Kylling et al. (1997), the observed wavelength dependence is due to photons being reflected by clouds, after which the photons are scattered downward by Rayleigh scattering above the clouds and transmitted through the clouds to the ground surface. CMF has been used to evaluate the cloud effects on irradiance, actinic flux, and photolysis rate. We also use CMF in our analysis of the actinic flux profile at a green wavelength.

In this paper we describe the instrument and measurements in Sect. 2. The simulation method for the actinic flux profiles is presented in Sect. 3. The results are shown in Sect. 4. Conclusions are drawn in Sect. 5.

\section{Instrument and measurements}

A light sensor has been developed at KNMI using a commercial green LED (light-emitting diode) with a diameter of $5 \mathrm{~mm}$ made of gallium phosphide $(\mathrm{GaP})$. It is mounted in the centre of a $10 \mathrm{~cm}$ Styropor (polystyrene) sphere. A picture of the light sensor and sphere is shown in Fig. 1. The sphere acts both as a thermal insulation and a light diffuser. The detector and amplifier are temperature-stabilized at $25^{\circ} \mathrm{C}$. The instrument has been designed to have uniform response to sunlight. The point on the sphere where the LED sensor was inserted is called the north pole. The senor was glued at a position in the sphere where its sensitivity to sunlight was comparable when the sphere was lit from the north or the south pole. After the instrument was completed, it was held in a beam of sunlight that would enter a single window in an otherwise dark room. The response of the instrument was checked by rotating the sphere. If it was found to be more sensitive on one side, a black permanent marker pen was used to make marks on that side. Typically it was found that the sensitivity was higher (10\% or so) on the equator compared to the poles. This process was repeated until the response of the instrument varied less than $2 \%$ when the sphere was rotated. So the spheres have a number of black lines around the 


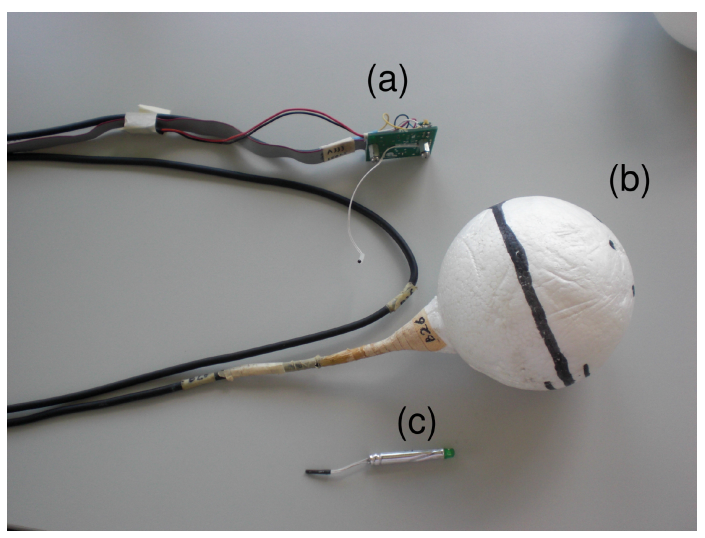

Figure 1. Photo of the light sensor: (a) data transmitter, (b) sphere, (c) green LED.

equator to make the sensitivity uniform. The light sensor is not absolutely calibrated, and the measured actinic profile is in an arbitrary unit. However, before launching a light sensor, intercomparison measurements were performed on the ground together with one reference light sensor which is kept and not used for launching. If the reference sensor does not change with time, the actinic flux profiles measured with different sensors should be intercomparable. The exact spectral response of the light sensor is not measured. The spectral response of the same type of sensor has been shown by Brooks and Mims III (2001) in their Fig. 2 for the RadioShack green LED. The spectral response of the RadioShack green LED covers the wavelength range $450-580 \mathrm{~nm}$ with the peak value at about $560 \mathrm{~nm}$ and centre at $525 \mathrm{~nm}$. At present, the light sensor is mainly used to evaluate the cloud effects on actinic flux profiles. The green light sensor is chosen because it is not sensitive to ozone and water vapour absorptions, so that the impacts of clouds and aerosols on the actinic fluxes can be separated from the effects of gas absorptions.

The light sensor is launched together with the ozonesonde balloon, and the data are transmitted during flight. The light sensor is attached to a line and located at about $20 \mathrm{~m}$ below the balloon and $2 \mathrm{~m}$ below the ozonesonde. Because the payloads of the balloon rotate during flight, the light sensor could rotate in the shadow of the balloon when the balloon is at high altitude and the sun is almost overhead $\left(\mathrm{SZA}<30^{\circ}\right)$. This can be identified as a sharp dip in the measured actinic flux profile from the $1 \mathrm{~s}$ data record. The measurements impacted by the shadow of the balloon were removed before the data are averaged over $10 \mathrm{~s}$ and stored. The instrument weighs about $100 \mathrm{~g}$, is low cost, and can be reused after recovery. The ozonesonde is launched at 11:30 UTC on every Thursday at $\mathrm{De} \operatorname{Bilt}\left(5.18^{\circ} \mathrm{E}, 52.10^{\circ} \mathrm{N}\right)$, the Netherlands. The vertical velocity of the ozonesonde is typically $5 \mathrm{~m} \mathrm{~s}^{-1}$ and reaches an altitude of $30-35 \mathrm{~km}$ in about $100 \mathrm{~min}$. After the burst of the balloon, the sonde drops back to the ground with a parachute in about $60 \mathrm{~min}$. The data stream includes ascending and descending values of time, altitude, pressure, temperature, relative humidity ( $\mathrm{RH})$, ozone partial pressure, and actinic flux. The trajectory of the balloon is obtained from GPS data.

\section{Methods for the actinic flux profile simulations}

\subsection{Radiative transfer modelling and input data}

The Doubling-Adding KNMI (DAK) radiative transfer code (De Haan et al., 1987; Stammes et al., 1989; Stammes, 2001) is used to simulate the measured actinic flux profiles. DAK is a 1-D plane-parallel radiative transfer code with a pseudo-spherical correction for solar zenith angles (SZAs) greater than $75^{\circ}$. Because the measurements were made at noon, the SZAs are usually smaller than $75^{\circ}$ except in December and January. The DAK model was used by van Weele et al. (1995) in the UV-A actinic flux calculations. The DAK-simulated surface shortwave broadband irradiances have good agreement with the ground-based BSRN (Baseline Surface Radiation Network) measurements for clear-sky and overcast water cloud scenes (Wang et al., 2009, 2011). In this paper, the DAK simulations were performed for $\lambda=550 \mathrm{~nm}$ to represent the green wavelength range. Absorption by ozone is taken into account by using the shape of a climatological ozone profile and scaling it to the assimilated total ozone column at 12:00 UTC using OMI total ozone data (Eskes et al., 2003). The ozone absorption cross section is taken from H. S. Johnston (personal communication, 1997, http://satellite.mpic.de/spectral_atlas/cross_ sections/Ozone/O3_Johnston(1997)_298K_408-599nm.txt). Water vapour absorption is not taken into account in the simulations because it is weak at $550 \mathrm{~nm}$. The Rayleigh scattering cross section is calculated according to Bodhaine et al. (1999).

For clear-sky scenes, aerosol optical thickness (AOT) data are taken from the SPUV sun photometer at Cabauw $\left(4.93^{\circ} \mathrm{E}, 51.97^{\circ} \mathrm{N}, 20 \mathrm{~km} \mathrm{SW}\right.$ of De Bilt) because AOT is not measured in De Bilt. For cloudy scenes, a default AOT of 0.18 at $550 \mathrm{~nm}$ is used, which is close to the climatological value for Cabauw. The LOWTRAN rural aerosol profile is used, with addition of a well-mixed aerosol layer from the surface to the top of the boundary layer for clear-sky scenes. The latter is determined from the lidar measurements in Cabauw.

For cloudy scenes, the sky is assumed to be fully overcast (cloud fraction of 1). The cloud optical thickness, cloud phase, effective radius, cloud top height, and cloud mask are obtained from the SEVIRI/MSG Cloud Physical Properties (CPP) product (Roebeling et al., 2006). This product is available every $15 \mathrm{~min}$. The pixel size of a SEVIRI measurement is about $3 \mathrm{~km} \times 6 \mathrm{~km}$ (longitude $\times$ latitude) in the Netherlands. During one actinic flux profile measurement there are 10 SEVIRI images taken from 11:30 to 13:45 UTC. 

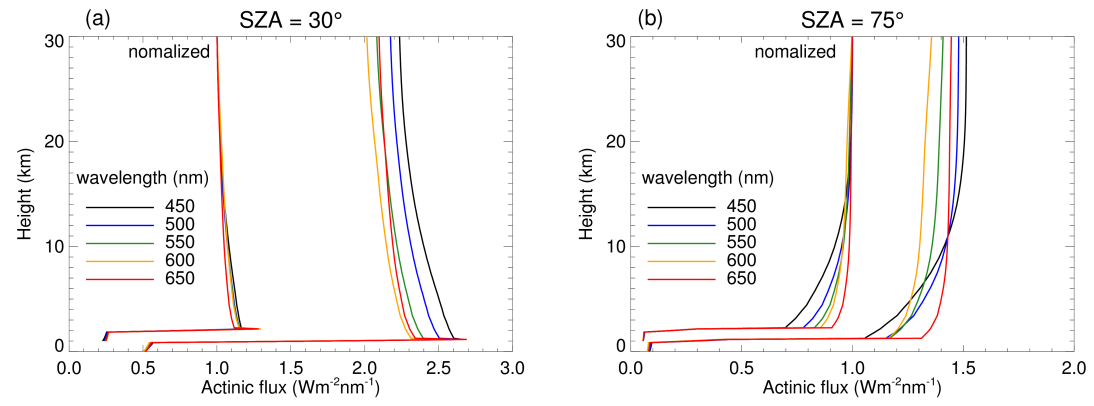

Figure 2. Simulated actinic flux profiles at wavelengths of $450,500,550,600$, and $650 \mathrm{~nm}$ at SZA $=$ (a) 30 and (b) $75^{\circ}$. The cloud top is at $1.3 \mathrm{~km}$, cloud base is at $0.8 \mathrm{~km}$, and cloud optical thickness is 30 . Particle size of the water cloud is $10 \mu \mathrm{m}$. The aerosol optical thickness is 0.18 at $550 \mathrm{~nm}$ and surface albedo is 0.15 . At every wavelength the normalized actinic flux profile is the simulated actinic flux profile divided by the actinic flux at $30 \mathrm{~km}$. The normalized actinic fluxes are shifted $1 \mathrm{~km}$ up in the $y$ axis.

The cloud properties are selected from every SEVIRI image according to the time and geolocation of the balloon along its trajectory from launching to landing. These times and locations match exactly between the SEVIRI images and the radiosonde. Cloud properties are also selected when the balloon reaches five special altitudes: surface (launching, landing), cloud top height (ascending, descending), and maximum flight altitude. At these five points, the cloud properties are selected at the exact geolocation of the balloon but on the SEVIRI images taken at the time closest to the balloon measurement. The resulting 15 COT values from SEVIRI, with possibly two COT values from one image at two geolocations, largely follow the COT variations during one profile measurement. The cloud top height is determined from the peak value in the actinic flux profile and is checked with the cloud top height in the SEVIRI data. Note that the location of the actinic flux peak in cloudy scenes depends primarily on the cloud optical thickness, surface albedo, and solar zenith angle (assuming no aerosols). At small solar zenith angle, the actinic flux peak usually occurs slightly below the cloud top for optically thick clouds over dark surface (Madronich, 1987). The cloud base heights are taken from operational ceilometer measurements in De Bilt and Cabauw. The cloud scattering phase matrices were calculated using Mie theory for water droplets and using the effective radius from SEVIRI CPP data. The effective radius and cloud extinction coefficient are assumed to be constant inside the clouds. For example, if the cloud occupies five $100 \mathrm{~m}$ thick layers of the atmospheric model profile and has a COT of 10 , then every layer has a COT of 2. The DAK simulations are performed for 15 COT values covering the SEVIRI data. COT of 1 and 100 are also used in the DAK simulations to improve the interpolations.

Although there are 15 collocated COT values from SEVIRI during every actinic flux profile measurement, the COT may not be representative of the actual cloud conditions during an actinic flux profile measurement, because of retrieval uncertainty and subpixel cloud variability. The error of the COT from SEVIRI is about $15 \%$ (http://msgcpp.knmi. nl/mediawiki/index.php/MSGCPP_product_description). Including the mismatching of the SEVIRI measurement and actinic flux profile measurement, the uncertainty of COT estimation during actinic flux profile measurement is probably larger.

In DAK, the altitude levels are specified using the atmospheric profile (height, pressure, temperature) which is taken from the ozonesonde data. In order to get high-verticalresolution simulations inside the clouds, the thickness of one atmospheric profile layer is about $100 \mathrm{~m}$ for the cloudy atmosphere and coarser $(\sim 500 \mathrm{~m})$ for the cloud-free atmosphere. Above $30 \mathrm{~km}$, the atmospheric profile is extended using the midlatitude summer atmospheric profile (Anderson et al., 1986). The surface albedo is assumed to be 0.15 for grasscovered surface, because the surroundings of the De Bilt site are largely covered by green grass throughout the year. As the altitude of the instrument increases, the surface albedo might change because the instrument sees a larger area. The actinic flux profiles are simulated at different SZA and COT values. Then, the DAK-simulated actinic fluxes are interpolated at the actual SZA and COT values along the flight track to get the best simulation for a single measured actinic flux profile.

\subsection{Wavelength dependence of actinic flux profile}

Because we do not know the exact spectral response of our green LED, we have chosen in this paper the wavelength of $550 \mathrm{~nm}$ to represent the wavelength band of the LED. Here a sensitivity study is performed using DAK to check the wavelength dependence of the actinic flux profile. The actinic flux profile is simulated at $450,500,550,600$, and $650 \mathrm{~nm}$ for a cloudy scene. These wavelengths cover the green LED spectral response completely. The DAK inputs of aerosol, atmospheric profile, ozone, and surface albedo data have been described in Sect. 3.1. The water cloud layer is located from 0.8 to $1.3 \mathrm{~km}$ altitude, and the cloud optical thickness is 30 . The particle size (effective radius) of the water clouds is $10 \mu \mathrm{m}$. 
The cloud fraction is 1 (overcast). The extraterrestrial solar irradiance is assumed to be $1 \mathrm{~W} \mathrm{~m}^{-2} \mathrm{~nm}^{-1}$ perpendicular to the solar beam for every wavelength in the simulation. The simulated actinic flux profiles for this cloudy case with and without normalization are shown in Fig. 2 at SZA of 30 and $75^{\circ}$, respectively. The normalized actinic flux profiles are the simulated actinic flux profiles divided by the actinic fluxes at $30 \mathrm{~km}$.

As shown in Fig. 2, the simulated AFs have a strong wavelength dependence above the cloud due to Rayleigh scattering. Inside the cloud, there is hardly any wavelength dependence of AF because multiple Mie scattering by the cloud particles is dominant. Below the cloud, the wavelength dependence of actinic flux is also small. In this optically thick cloud case, photons scattered above the cloud top cannot easily transmit through the cloud layer; consequently there is almost no wavelength dependence of AF below the cloud. A wavelength dependence of the actinic flux below the cloud only occurs if the cloud is optically thin (say COT of 8).

The actinic flux profiles have a similar shape for the five wavelengths at $\mathrm{SZA}=30^{\circ}$ (see Fig. 2a). After normalization at $30 \mathrm{~km}$, the actinic flux profiles for different wavelengths almost overlap. Similar behaviour occurs at SZAs smaller than about $60^{\circ}$. However, when the SZA is getting larger than $60^{\circ}$, the actinic flux profile shape depends strongly on the wavelength. After being normalized at $30 \mathrm{~km}$, the five actinic flux profiles have large differences at the cloud top. An example is shown in Fig. $2 b$ for a SZA of $75^{\circ}$. This indicates that we can use the actinic flux profile shape at $550 \mathrm{~nm}$ to represent the actinic flux profile shape of the wavelength range 450$650 \mathrm{~nm}$ at small SZAs but not for large SZAs.

\section{Results}

\subsection{Actinic flux profile measurements}

Actinic flux profiles were measured during 63 launches, of which 30 launches were made in 2006, 27 in 2007, 4 in 2008, and 2 in 2010. The flight trajectories were mainly in the range of $4-9^{\circ} \mathrm{E}$ and $51-53^{\circ} \mathrm{N}$. Most launches had one ascending profile and one descending profile; some launches had only ascending profiles, while the descending profiles were not received properly. In the data set there are 14 clear-sky profiles distributed over 9 days, and the rest are cloudy profiles.

All the profiles are illustrated in Fig. 3a. The profiles are separated into two groups, because of a calibration issue which occurred in the year 2007. Figure $3 \mathrm{~b}$ shows the ratio between the global irradiance measured at the ground by a pyranometer and the actinic flux at $4 \mathrm{~m}$ height (the lowest point of the profile) at 11:30 UTC as a function of SZA. The data points shown as filled circles are measured from 1 June to 21 December 2006. As shown in Fig. 3b, the ratio seems quite consistent in 2006 except for two outliers which are caused by very small actinic fluxes. The scatter of the points in 2006 could be due to partly cloudy scenes. This indicates that the instruments are comparable to each other and the sensors do not depend on the SZA and temperature. The calibration issue can be identified from the ratio in 2007 which appears to have a different magnitude from that in 2006 and is too variable. The ratio of irradiance to actinic flux at the surface could be used to rule out large instrument errors before launch, such as the calibration issue in 2007. The ratio is not suitable for the calibration of the light sensor because the relationship between irradiance and actinic flux is general non-linear (Madronich, 1987). The ratio is dependent on solar zenith angle, surface albedo, and presence of the direct solar beam, which requires cloud and aerosol information. In the comparison with DAK-simulated profiles, the measured actinic flux profiles were normalized at $30 \mathrm{~km}$ and are thus in an arbitrary unit.

As shown in Fig. 3a, the actinic flux profiles have large vertical variability below $10 \mathrm{~km}$ because of the presence of clouds and aerosols. Above $10 \mathrm{~km}$, the profiles are less variable. The ascending and descending profiles often overlap between 15 and $35 \mathrm{~km}$ altitude, because the sonde falls down rapidly after the burst of the balloon. The descending profiles often do not extend down to the surface, because of loss of radio signal at long distance.

\subsection{Impact of aerosols and clouds on actinic flux profiles}

Figure 4a shows four clear-sky actinic flux profiles measured on 11, 12, and 13 September 2006 and 17 April 2010. The clear-sky scenes are determined from MODIS images and total sky imager data at Cabauw. Figure $4 \mathrm{~b}$ shows the AOT measured at Cabauw for the same days. The smallest SZA values during the actinic flux profile measurements are about $42^{\circ}$ on 17 April 2010 and $48^{\circ}$ for the measurements in September 2006. According to the lidar extinction coefficient profiles at Cabauw, the boundary layer heights at 11:30 UTC for the 4 days are $1.0 \mathrm{~km}$ (17 April 2010), 1.2, 0.5 , and $0.7 \mathrm{~km}$ (11-13 September 2006). Because the AOT varies during the day (Fig. 4b), we can expect that the AOT also varies along the flight track. On 17 April 2010 the AOT is about 0.1, which is the lowest value in the 4 days. On this day the actinic flux profile above the boundary layer is also lower than on the other days. The AOT is about 0.3 on 12 September (12:00 UTC) and about 0.4 on 11 and 13 September. This agrees with the actinic flux measurements; namely, the actinic fluxes at $1-5 \mathrm{~km}$ on 11 and 13 September are slightly larger than those on 12 September. Due to the scattering by aerosols, the actinic flux is enhanced at the top of the aerosol layer and above. This further demonstrates the consistency of the instruments when the intercomparison works well. The upper part of the actinic flux profiles ( $>5 \mathrm{~km}$ ) has no correlation with the AOT at Cabauw, because of the spatial variation of AOT and surface albedo. 

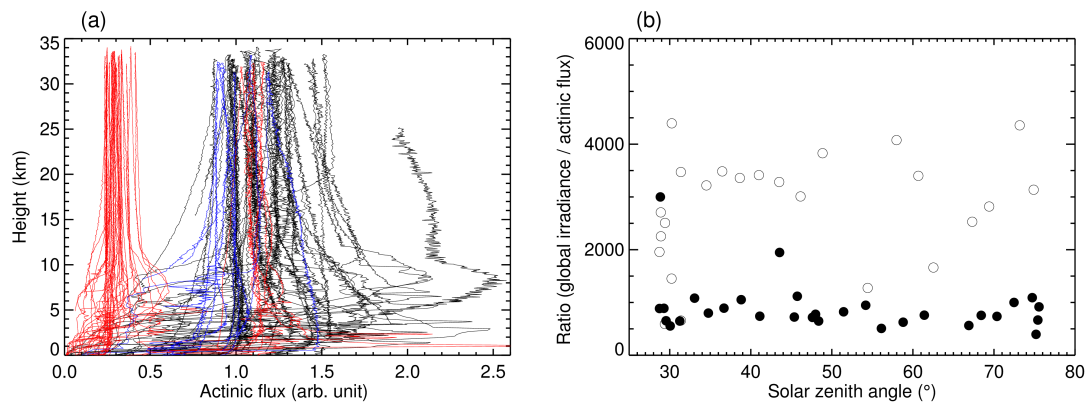

Figure 3. (a) Measured actinic flux profiles in 2006 (black lines), 2007 (red lines), 2008, and 2010 (blue lines). (b) Ratio between the global irradiance at the ground measured at 11:30 UTC at De Bilt and the actinic flux profile measurement at $4 \mathrm{~m}$ height at 11:30 UTC at De Bilt. Results for 2006 are marked as filled circles; results for 2007 are in open circles.
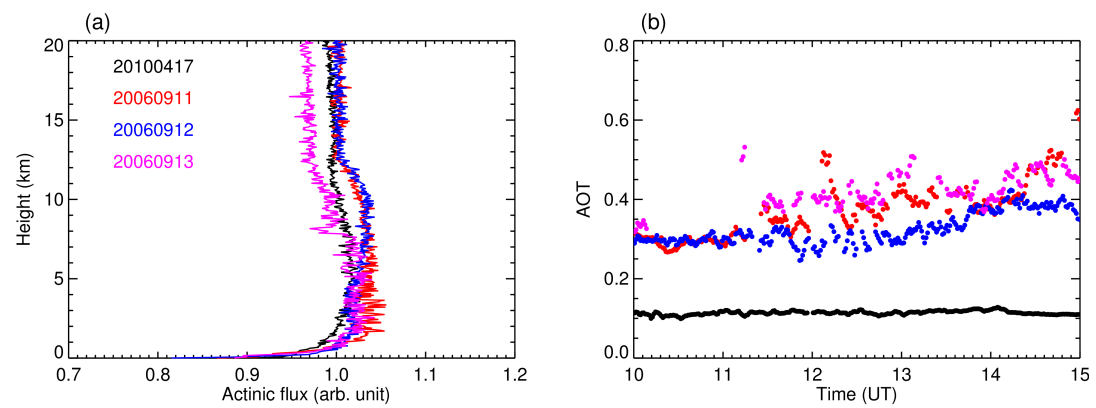

Figure 4. (a) Clear-sky actinic flux profiles measured on 11-13 September 2006 and 17 April 2010. (b) AOT at $501 \mathrm{~nm}$ measured in Cabauw for the same days. The profiles are the original measurements, not normalized.

The actinic flux profiles (ascending profiles only) for six cloudy cases are shown in Fig. 5. The actinic flux profile peaks at the upper boundary of the high-RH layer. Inside clouds, $\mathrm{RH}$ values are close to $100 \%$. RH values at temperatures below $0{ }^{\circ} \mathrm{C}$ are corrected to $\mathrm{RH}$ with respect to ice, which is larger than the measured $\mathrm{RH}$ with respect to water. When the balloon is close to the cloud top, the light sensor detects a sharp peak in the actinic flux profile (e.g. Fig. 5ad). Inside the cloud, the actinic flux profile decreases until the base of the cloud and becomes relatively stable below the cloud.

The altitude dependence of the directional radiation inside a scattering atmosphere or cloud layer depends mainly on the optical depth $\tau$ (and its vertical distribution), solar zenith angle, and surface albedo (Stammes et al., 1989). The fact that the peak in the diffuse radiative flux is not located at the top of the cloud layer, but rather inside the layer, is due to enhanced multiple scattering in the top layer of clouds. Since direct sunlight is incident at the top of the clouds, the amount of scattered sunlight first increases going from the top downwards due to multiple scattering, reaches a maximum, and then decreases again. In first order, the diffuse radiative flux is linear in $\tau$ at the top of the clouds. It has been found by Stammes et al. (1989) that for an isotropically scattering cloud the downward flux increases when de- scending into the cloud layer for high sun $\left(\mu_{0}>0.5\right)$ but decreases from the cloud top for low sun $\left(\mu_{0}<0.5\right)$. Simulations for actinic fluxes have been done by Madronich (1987) using a simple isotropic model and a delta-Eddington model. This finding was corroborated with multiple-scattering calculations. In the field of actinic flux studies, the peak below the cloud top has been found in actinic flux calculations and in balloon measurements (van Weele et al., 1995; van Weele, 1996; Vilà-Guerau de Arellano et al., 1994).

As can be seen in Figs. 4-5, the actinic flux profiles have small, high-frequency variations. The variations are relatively larger in cloud-free scenes and above clouds where the instrument is exposed to direct sunlight and smaller inside and below clouds, where mainly diffuse radiation is present. It is probably caused by the rotation of the balloon and the light sensor (sphere). The instrument has been adjusted before launch to have less than $2 \%$ variation during rotation (see Sect. 2). Therefore, it is interesting to check the relative variation using real profile measurements. The relative variation is determined using the actinic fluxes between 15 and $30 \mathrm{~km}$ in every ascending profile. In 63 ascending profiles, 59 profiles have relative variations smaller than $2 \%$; 2 profiles have relative variations of 2.1 and $3.2 \%$, respectively; and 2 profiles were excluded because of not reaching high altitude. The mean variation is $0.7 \%$ for the 61 profiles. 

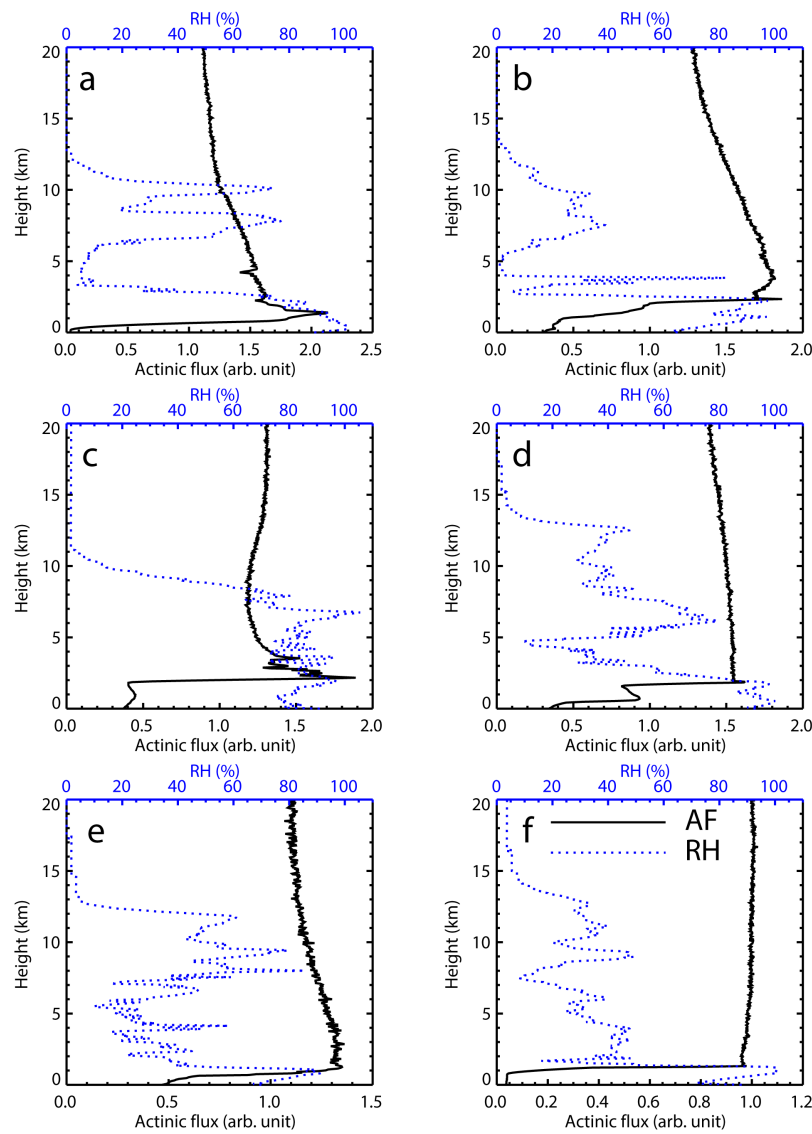

Figure 5. Actinic flux (AF) and relative humidity (RH) profiles for cloudy scenes measured on (a) 15 June 2006 $\left(\mathrm{SZA}=28.8^{\circ}\right)$, (b) 22 June $2006\left(\mathrm{SZA}=28.7^{\circ}\right)$, (c) $10 \mathrm{Au}-$ gust $2006\left(\mathrm{SZA}=36.7^{\circ}\right)$, (d) 5 September $2006\left(\mathrm{SZA}=45.4^{\circ}\right)$, (e) 6 September $2006\left(\mathrm{SZA}=45.7^{\circ}\right)$, and (f) 21 December 2006 $\left(\mathrm{SZA}=75.6^{\circ}\right)$. The profiles are ascending measurements and are not normalized. The SZA value is at 11:30 UTC, the start of the profile.

If the data between 20 and $25 \mathrm{~km}$ are used for the test, the mean variation is also about $0.7 \%$. This demonstrates that the instrument has a quite uniform response to sunlight.

\subsection{Actinic flux profiles compared with surface radiation measurements}

Figure 6a shows the ratio between the actinic flux below the cloud base close to the surface and at the cloud top (the peak of the actinic flux profile) ( $R_{\text {base/top }}$ ) as a function of the surface solar irradiance measured in De Bilt for 63 ascending profiles. Although some profiles have a calibration issue, this has no impact on the ratio calculated from the same profile. The ratio $R_{\text {base/top }}$ is determined by cloud optical thickness, surface albedo, and solar zenith angle.

Similar to the CMF used in UV radiation studies (e.g. Antón et al., 2012), ratios of the actinic flux profiles in cloudy scenes and clear-sky scenes are calculated at cloud top $\left(\mathrm{CMF}_{\text {top }}\right)$ and below the cloud base (close to the ground surface; $\mathrm{CMF}_{\text {base }}$ ). For clear-sky scenes, the CMF is 1 by definition. In principle, the clear-sky actinic flux profile should be calculated using a radiative transfer model using an atmospheric state which is identical to the cloudy scene. Here, we used the atmospheric state (temperature, pressure, aerosol optical thickness) on the clear-sky day of 11 September 2006 as a reference for all the cloudy actinic flux profiles in 2006. However, the clear-sky profiles are simulated at the same SZA as occurred for the cloudy profiles. The AOT is 0.34 on 11 September. According to the scaling factor derived from the clear-sky actinic flux profiles for 11 September 2006, the DAK-simulated clear-sky actinic flux profiles are converted to the same scale as the measured actinic flux profiles. Otherwise, the calculated CMF would not fulfill the definition of 1 for clear-sky scenes. The simulation of the clear-sky actinic flux profile is discussed in Sect. 4.4.

In Fig. $6 \mathrm{~b}$ the CMF as a function of COT is shown for cloud top and cloud base, which we denote by $\mathrm{CMF}_{\text {top }}$ and $\mathrm{CMF}_{\text {base }}$. The lines are simulations of $\mathrm{CMF}_{\text {top }}$ and $\mathrm{CMF}_{\text {base }}$ for $\mathrm{SZA}=60$ and $30^{\circ}$ assuming single-layer water clouds (effective droplet radius $8 \mu \mathrm{m}$ ) with cloud top at $2.3 \mathrm{~km}$ and cloud base at about $1.5 \mathrm{~km}$. As shown in Fig. 6b, most of the CMFs derived from the measurements are within the ranges of the simulated values. The CMF at cloud base decreases from 1 to about 0.05 with increasing COT. For the actinic flux at the surface, clouds have a shielding effect. The surface albedo is relatively small, so there is not much reflection between the cloud base and the surface. Therefore, the optically thicker the clouds, the less light can penetrate the clouds. At COT close to 0 , at cloud base there are some $\mathrm{CMF}_{\text {base val- }}$ ues of 1.4-1.5. This indicates that the actinic fluxes in cloudy scenes are larger than for the clear-sky scenes. This could occur when broken clouds are present and 3-D effects become important. Enhancement of surface actinic flux in the presence of broken clouds has been measured and explained in earlier studies (e.g. Lantz et al., 1996; Crawford et al., 2003). This enhancement can happen if the sun is not obscured by clouds and the diffuse actinic flux of clouds is larger than the diffuse actinic flux of clear sky (Crawford et al., 2003).

$\mathrm{CMF}_{\text {top }}$ increases with increasing COT. The enhancement of the actinic flux at cloud top is caused by multiple scattering at cloud top. As illustrated by the simulated CMFs in Fig. 6b, the CMF at cloud top has a stronger SZA dependence than the CMF at cloud base. For example, at COT of 40 , from SZA of 30 to $60^{\circ}$, the CMF changes 0.7 at cloud top and 0.2 at cloud base. This may partly explain the scatter of $\mathrm{CMF}_{\text {top }}$. $\mathrm{CMF}_{\text {top }}$ depends also on the cloud top height due to the height dependence of the clear-sky actinic fluxes. For the measured actinic flux profiles, the cloud top heights are in the range of $1-10 \mathrm{~km}$. At SZA $=60^{\circ}$, the clear-sky actinic fluxes can increase by $10 \%$ from 1 to $10 \mathrm{~km}$, and, consequently, the $\mathrm{CMF}_{\text {top }}$ can change by $10 \%$. The outliers of the $\mathrm{CMF}_{\text {top }}$ at $\mathrm{COT}<5$ could be due to the COT values used. For small 

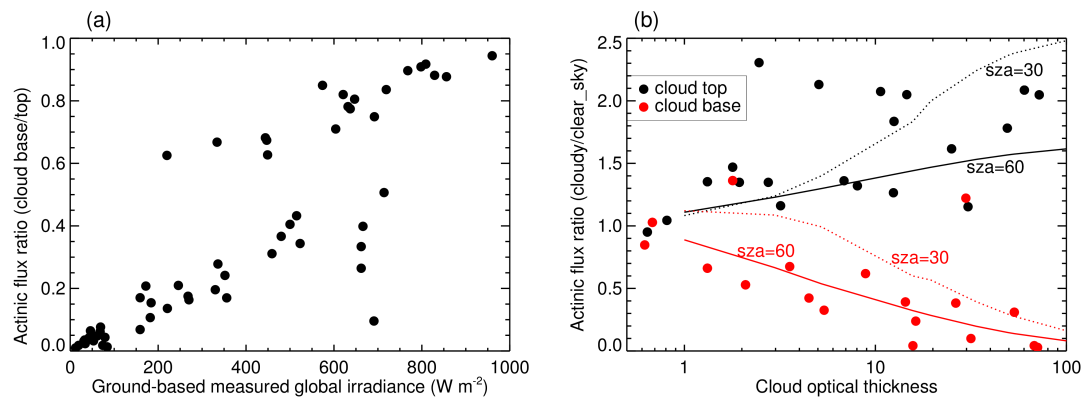

Figure 6. (a) Ratio between the measured actinic fluxes at cloud base and at cloud top vs. the measured global irradiance at the surface, for all data. (b) Ratio between measured actinic fluxes of cloudy and clear-sky scenes (CMF) at cloud top (black) and cloud base (red) vs. SEVIRI cloud optical thickness at 11:30 UTC for data in 2006. The dots are measurements; the lines are simulations for CMF at cloud top and cloud base for $\mathrm{SZA}=30$ and $60^{\circ}$.

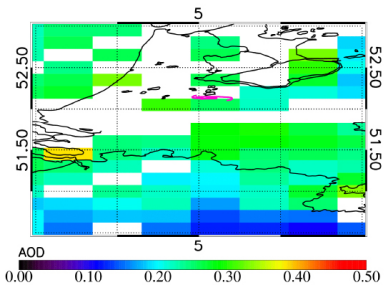

(b)

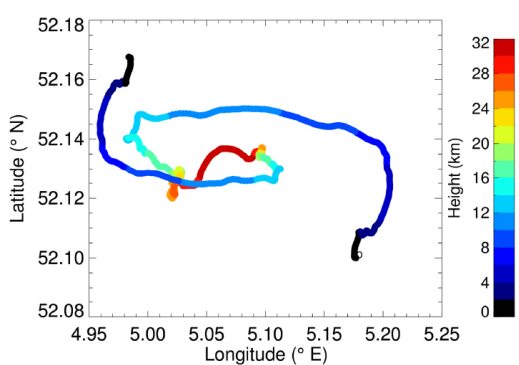

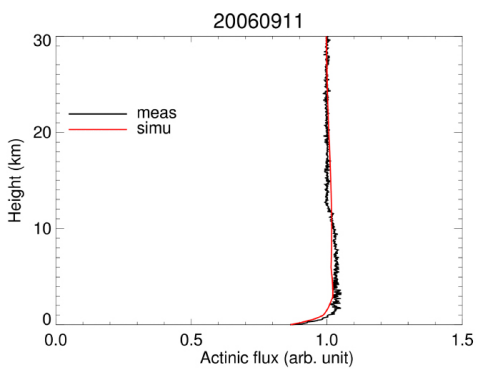

Figure 7. Clear-sky case on 11 September 2006. (a) MODIS aerosol optical thickness image at 11:45 UTC; the purple curve shows the trajectory of the balloon. (b) Trajectory of the balloon, with its height indicated by colour. The location of De Bilt is marked with a circle. (c) Measured actinic flux profile and simulated actinic flux profile.

local clouds, the COT from SEVIRI may not be representative of the clouds "seen" by the light sensor. This can happen because of mismatching between the SEVIRI pixel and the balloon location or due to the subpixel clouds in the SEVIRI retrievals.

If the assumed atmospheric state, especially AOT, is not the same as the actual atmospheric state, the CMF may not be 1 at $\mathrm{COT}=0$. According to our simulations, the ratio of clear-sky actinic flux for AOT of 0.25 and of 0.34 is 1.04 at the surface, 0.98 at $1 \mathrm{~km}$, and 0.99 at $10 \mathrm{~km}$ for $\mathrm{SZA}=60^{\circ}$. We estimate that the uncertainty in the CMF due to the AOT uncertainty is up to $5 \%$.

\subsection{Simulations of actinic flux profile for clear-sky scenes}

As shown in Fig. 4b, the AOT on 11 September 2006 varies from 0.3 to 0.5 between 11:00 and 14:00 UTC. This may indicate that the AOT is also spatially variable. This is confirmed by a MODIS AOT image which reveals a typical spatial variation in AOT between 0.2 and 0.4 for the Netherlands (see Fig. 7a). The missing AOT data are mostly caused by the presence of clouds. We used the DAK model to simu- late actinic flux profiles using AOT values varying from 0 to 0.5 . Then the simulated actinic flux profiles are interpolated to the measured AOT and SZA values on 11 September 2006. The simulated and measured actinic flux profiles are shown in Fig. 7c. The simulated actinic flux profile and the measured profile are normalized at $30 \mathrm{~km}$ with a scaling factor of 4.13 and 1.002, respectively. The simulated actinic flux profile closely follows the shape of the measured profile, although there are some small deviations. The simulated profile consists of several profiles having different AOT because the balloon moved both vertically and horizontally. In the simulated profile, when the balloon was below $1 \mathrm{~km}$, the AOT was 0.5 ; after the balloon moved above $1 \mathrm{~km}$, the AOT was 0.34 . AOT values of 0.5 and 0.34 occur at different locations, not in one vertical profile. As shown in the trajectory in Fig. 7b, the measured actinic flux profile is in fact three-dimensional, because the sonde drifts away from the launch location. This feature is more significant during cloudy conditions due to the large spatial variation of cloud optical thickness. 


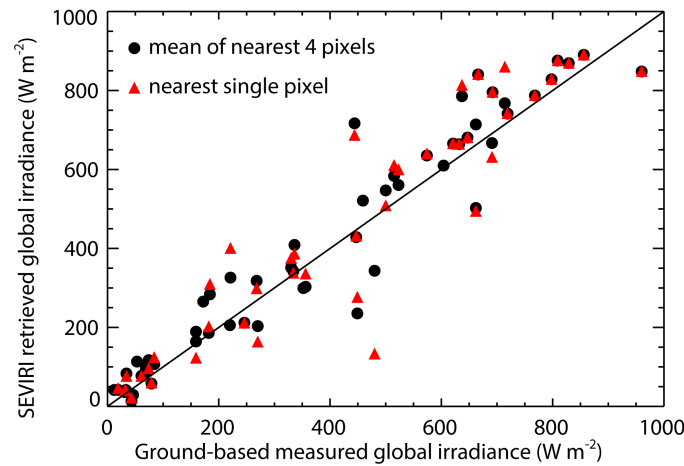

Figure 8. Scatter plot of SEVIRI-retrieved global irradiance at the surface (surface solar irradiance, SSI) vs. ground-based measured global irradiance at 11:30 UTC at De Bilt on all 63 actinic flux profile measurement days. The black line is the one-to-one line. The black dots indicate the mean SSI of all SEVIRI pixels in a $0.1^{\circ} \times 0.1^{\circ}$ (latitude $\times$ longitude) grid box. The red triangles indicates the nearest single-pixel SSI in the grid box.

\subsection{Simulations of actinic flux profiles for fully cloudy scenes}

Global irradiances derived from SEVIRI, called surface solar irradiances (SSI), are calculated using the SEVIRI COT derived from the CPP algorithm and aerosols from a monthly climatology (Greuell et al., 2013). In order to check the quality of the SEVIRI COT in the SSI calculations, we compared the SEVIRI SSI with the ground-based shortwave global irradiance measurement at De Bilt. On the 63 actinic flux profile measurement days, we compared SEVIRI SSI at 11:30 UTC with ground-based $10 \mathrm{~min}$ mean (11:30-11:40 UTC) pyranometer measurements of global irradiance in De Bilt. As shown in Fig. 8, the SEVIRI SSI and ground-based measurements agree well, with a correlation coefficient of 0.965 and a bias of $22 \mathrm{~W} \mathrm{~m}^{-2}$ (for the mean SSI). This suggests that the COT from SEVIRI is of good quality and the actinic flux profiles calculated using these COTs can be considered realistic. The mean SSI value of 4 SEVIRI pixels and the nearest single-pixel SSI are often quite different for SSI values between 200 and $800 \mathrm{~W} \mathrm{~m}^{-2}$. This is caused by the inhomogeneity of clouds. The cases where SSI $<200 \mathrm{~W} \mathrm{~m}^{-2}$ or SSI $>800 \mathrm{~W} \mathrm{~m}^{-2}$ usually correspond to fully cloudy or clear-sky scenes, respectively. Therefore, the COT of the single SEVIRI pixel that is closest to the balloon measurement time and location may not be representative of the clouds that actually determine the actinic flux profile.

The cloudy actinic flux profiles are simulated for five single-layer water cloud cases in 2006, of which the results are shown in Figs. 9-13. The original actinic flux profiles (without normalization) have already been shown in Fig. 5. The simulations are presented in the order of complexity of the cases. We start with the simplest case on 5 September (Fig. 9), which is followed by an optically very thick
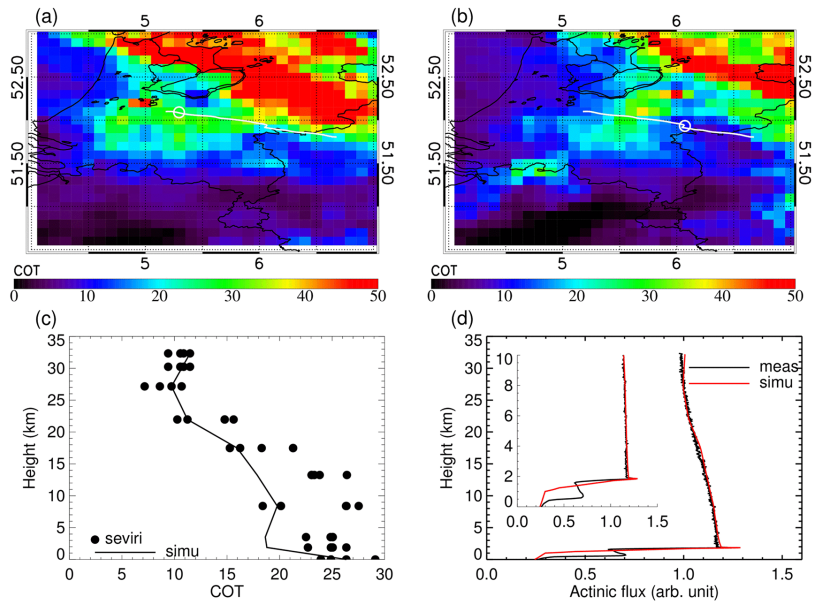

Figure 9. Cloudy-sky case on 5 September 2006. (a) SEVIRI cloud optical thickness image at 11:30 UTC (balloon launch) and (b) at 13:00 UTC (balloon maximum height). The flight track of balloon is indicated as a white line. The location of balloon at the time the SEVIRI image is taken is indicated as a white circle. (c) SEVIRI single-pixel cloud optical thickness values in $0.1^{\circ} \times 0.1^{\circ}$ (latitude $\times$ longitude) boxes along the trajectory of the balloon (dots) as a function of the height of the balloon. The COT values used in the simulations are connected by the black line. (d) Measured actinic flux profile and simulated actinic flux profile (both normalized at $30 \mathrm{~km}$ altitude, respectively). The actinic flux profile is also shown zoomed in at $0-10 \mathrm{~km}$.

cloudy case on 15 June (Fig. 10). During these launches, the COT mainly decreased during the balloon flight. On 22 June (Fig. 11) and 10 August (Fig. 12), the COT increased after launch and decreased when the balloon was at its maximum height. On 22 December (Fig. 13) the cloud layer was low and stable, but the SZA was large $\left(>75^{\circ}\right)$.

On 5 September 2006, the prevailing winds were from the west, so the balloon drifted eastwards. The SEVIRI cloud optical thickness images of 11:30 and 13:00 UTC are the closest to the start and end of the ascending profile. As shown in Fig. 9a, it was fully cloudy in De Bilt at 11:30 UTC when the ozonesonde was launched. The cloud optical thickness at 11:30 UTC was about 25 . The clouds were optically thicker in the north-east and optically thinner south of De Bilt. At 13:00 UTC the balloon drifted towards an area with COT of about 10 (see Fig. 9b). In the first $30 \mathrm{~min}$, the balloon flew over clouds having similar COT; then the clouds became thinner.

The COT for the trajectory of the balloon is shown as a function of balloon altitude in Fig. 9c. The SEVIRI pixels are selected within $0.1^{\circ}$ of the balloon lat/lon box, which usually has up to five pixels. The number of SEVIRI pixels can be less than five because of missing COT data (clearsky scene or no retrieval). Please note that the COT values in the maps are averaged over $0.1^{\circ} \times 0.1^{\circ}$ grids, while the COT values in Fig. $9 \mathrm{c}$ are given for every SEVIRI pixel. 

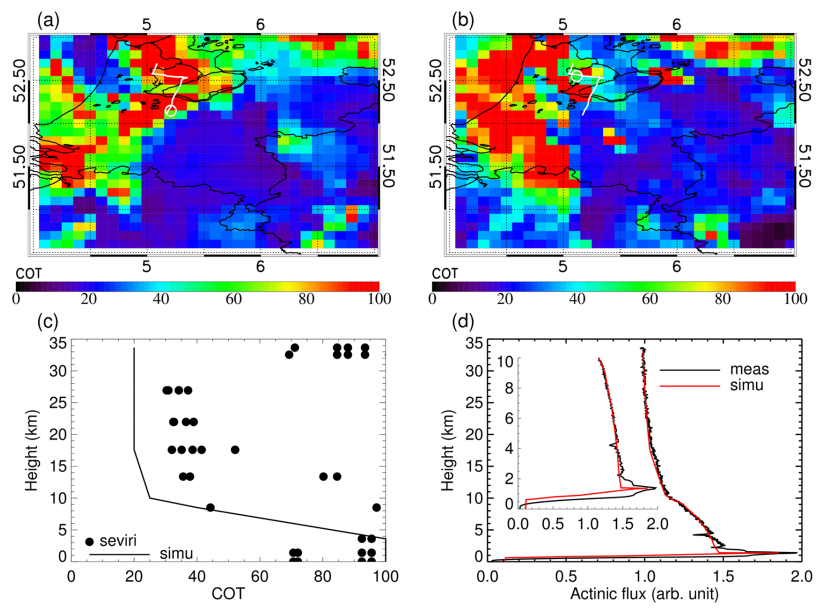

Figure 10. Same as Fig. 9 but for 15 June 2006.
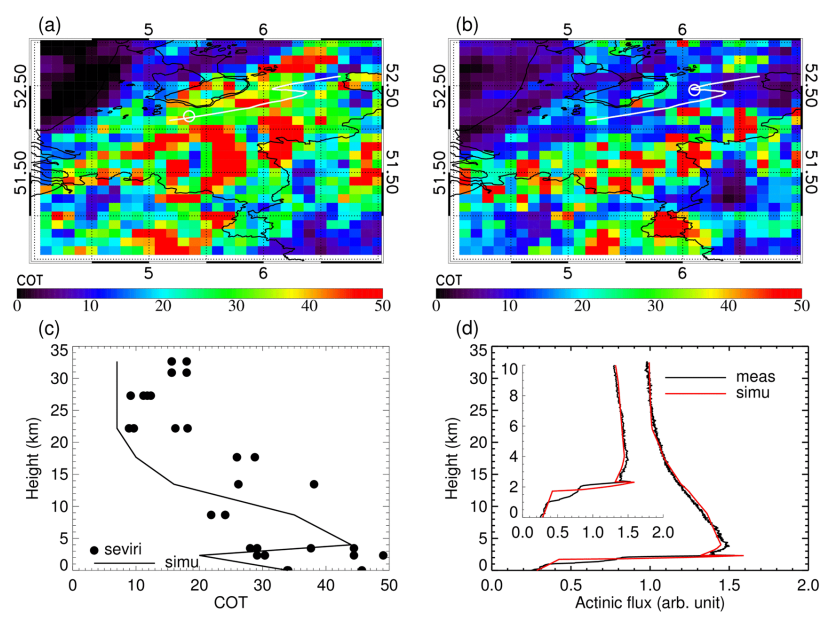

Figure 11. Same as Fig. 9 but for 22 June 2006.

If the balloon is above the cloud layer, variations in cloud optical thickness and cloud height will not produce sharp peaks in the actinic flux profile. However, all cloud variations along the flight track will show up in the actinic flux profile, because it includes the radiation from all directions and heights. The measured actinic flux profile in Fig. 9d shows two peaks, one at about $0.5 \mathrm{~km}$ and another at about $2 \mathrm{~km}$. This indicates that there are two cloud layers, with cloud top heights at about 0.5 and $2 \mathrm{~km}$. This is confirmed by the radar measurements at Cabauw, which show one cloud layer at $0.3-0.5 \mathrm{~km}$ and another cloud layer at $1-2 \mathrm{~km}$.

In the simulations the clouds are assumed to be single layer, with cloud top height at $2 \mathrm{~km}$ and cloud base height at $1 \mathrm{~km}$. Therefore, the simulated actinic flux profile has a single peak at $2 \mathrm{~km}$. The COT values used in the simulations are shown in Fig. 9c by the black line. The simulated actinic flux profile is in good agreement with the measured actinic flux profile. Although the measured and simulated ac-
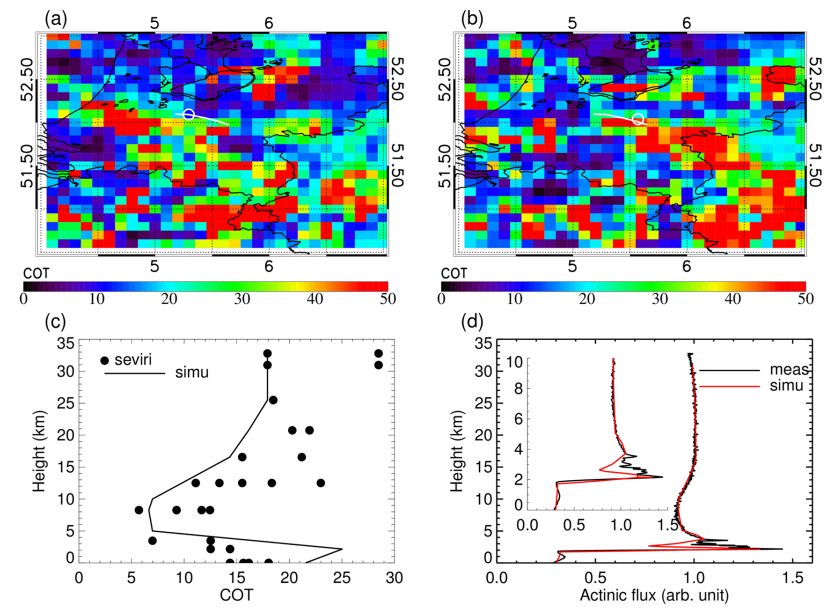

Figure 12. Same as Fig. 9 but for 10 August 2006.

tinic flux profiles are both normalized at $30 \mathrm{~km}$, this does not influence the shapes of the profiles. The consistency between the SEVIRI SSI and the ground-based global irradiance measurements suggests that the COT at De Bilt is quite representative. During the flight, the SZA changes from 29 to $34^{\circ}$, which has been taken into account in the simulation. The variation in the actinic flux profile shape is mainly due to variation in the COT.

The COT values and the measured and simulated actinic flux profiles for 15 June 2006 are shown in Fig. 10. The mean COT was very high, 95, at the launch in De Bilt, and the actinic flux profile showed a very strong peak at $1.5 \mathrm{~km}$. The balloon drifted to the north, then turned west, and reached an altitude of about $30 \mathrm{~km}$ over a region where the COT was small. The dips in the actinic flux profile at 2 and $4 \mathrm{~km}$ are probably related to optically thin clouds, cloud holes, cloud shadows, or clear-sky regions (Los et al., 1997).

The cloud top and base heights in the simulation were at 1.5 and $0.5 \mathrm{~km}$, respectively. The dips at 2 and $4 \mathrm{~km}$ were ignored in the simulation. As shown by the SEVIRI images of COT (Fig. 10a and b), clouds were getting thinner during the flight. The change of the measured actinic flux profile at $10 \mathrm{~km}$ suggests the change of COT, but unfortunately there is no SEVIRI image available at this time. Therefore, the COT was extrapolated at this altitude. Above $10 \mathrm{~km}$, the SEVIRI COT had to be reduced from about 30 to 20 to get a better simulation. Since the COT used in the simulation allows for closure with the measured ground-based global irradiance, the COT values used for the actinic flux profile simulation are possibly correct. In view of the uncertainty in the SEVIRI COT retrieval, the mentioned adjustment is also reasonable.

On 22 June 2006, the spatial variability in the SEVIRI COT along the balloon flight track is considerable (Fig. 11a and b). As shown in Fig. 11c, the COT decreases along the flight track and shows a large scatter. Between 10 and $20 \mathrm{~km}$ altitude, there are often only two COT values available in 

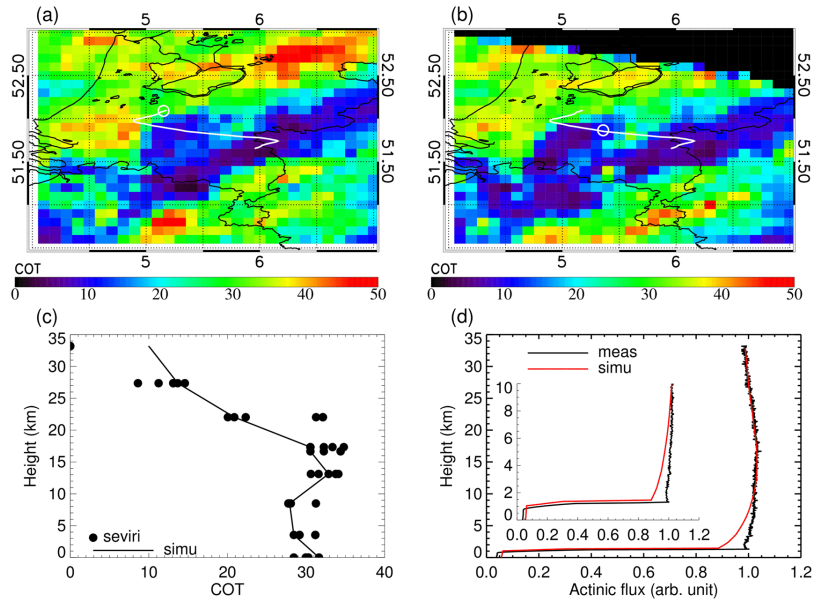

Figure 13. Same as Fig. 9 but for 21 December 2006. (b) The SEVIRI image was acquired at 12:45 instead of 13:00 UTC.

the $0.1^{\circ}$ box in the SEVIRI image instead of two COT values, which suggests some clear-sky pixels. At launch the COT was about 30 , and at $2 \mathrm{~km}$ altitude the COT decreased slightly. In the simulation, the cloud top height and base height were 3 and $2 \mathrm{~km}$, respectively. When the balloon passed through the cloud top, the flux profile showed a sharp peak at $3 \mathrm{~km}$. When the balloon was flying at $4 \mathrm{~km}$, the COT of underlying clouds increased, forming the broad peak at $3-6 \mathrm{~km}$ in the actinic flux profile. The simulated actinic flux profile follows the measured actinic flux profile shape very well. The actinic flux profile below cloud top decreases in two steps, which does not occur in the simulated profile. According to the measured actinic flux profile, cloud base could be at $1 \mathrm{~km}$ and the cloud optical thickness increased during the ascent from 1 to $3 \mathrm{~km}$.

On 10 August 2006 (Fig. 12), the clouds are optically thinner than the clouds described in the previous cases. According to SEVIRI, the COT was only about 15 at the launch in De Bilt. The main cloud layer was at $3 \mathrm{~km}$. As can be seen from Fig. 12d, the balloon went through several cloud layers between 2 and $5 \mathrm{~km}$. The balloon passed over some optically thin clouds when it was at $5-10 \mathrm{~km}$ altitude; then the COT increased again. The simulated cloud base and top heights were 2 and $3 \mathrm{~km}$, respectively. As shown in Fig. 12d, the simulated actinic flux profile follows the general shape of the measured profile, and the largest peak in the measurement is reproduced in the simulation.

The previously described cases all have SZAs smaller than $60^{\circ}$, so the application of a pseudo-spherical correction is not needed. However, during the actinic flux profile measurement on 21 December 2006 (Fig. 13), the SZA values ranged between 75 and $78^{\circ}$; therefore the pseudo-spherical correction has to be applied in the actinic flux profile simulations. Based on radar measurements in Cabauw, the cloud layer was very close to the ground surface and the cloud top height was

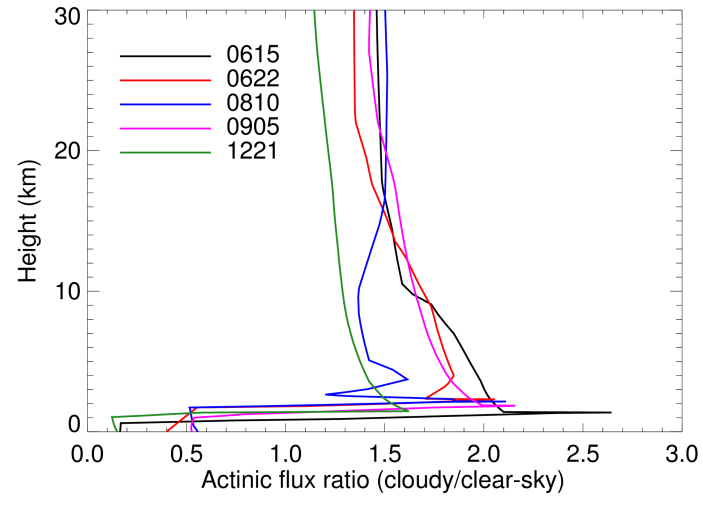

Figure 14. Simulated actinic flux ratio (cloudy/clear sky) for the cloudy cases in Figs. 9-13.

$1 \mathrm{~km}$. Although it was winter, the surface temperature was about $7{ }^{\circ} \mathrm{C}$ at the launch in De Bilt and there was no snow on the surface. As presented in Fig. 13a the SEVIRI COT is about 30 in De Bilt and relatively stable until the balloon reaches an altitude of $20 \mathrm{~km}$, where the COT starts to decrease. The pixel-to-pixel variation of COT is small. Therefore, this should be a simple case to simulate. As shown in Fig. 13d, the simulated actinic profile agrees well with the measured profile shape above $10 \mathrm{~km}$ and below the cloud top. However, the simulated actinic flux profile from cloud top $(1.5 \mathrm{~km})$ to about $10 \mathrm{~km}$ is much smaller than the measured actinic flux profile. As discussed in Sect. 3, for this case the wavelength dependence of actinic flux is important. The agreement between simulated and observed actinic flux profile might be improved if the simulations were performed at a fine wavelength grid and convolved with the spectral response function of the LED. The simulations should also use the solar irradiance spectrum over the LED spectral range instead of a constant value $\left(1 \mathrm{~W} \mathrm{~m}^{-2} \mathrm{~nm}^{-1}\right)$ as used in this paper.

A challenge for the DAK model appears to be the simulation of the actinic flux profile of 6 September 2006 (see Fig. 5e). The actinic flux profile of this day is similar to the clear-sky profiles, without sharp peaks. However, the value of the actinic flux profile above the cloud top is larger than for the clear-sky scenes. According to the total sky imager data at Cabauw and MODIS Terra $1 \mathrm{~km}$ resolution imagery, there were many small broken clouds on this day. Since SEVIRI cannot resolve the small broken clouds, the COT is quite low, about $1-3$. This case probably requires a $3-D$ radiative transfer model to correctly simulate the actinic flux profile.

The simulated actinic flux ratio (cloudy / clear sky) (CMF) for the cloudy cases of Figs. 9-13 is presented in Fig. 14. The simulated cloudy actinic flux profiles have already been shown in Figs. 9-13 after normalization. The variation of CMF in a single profile is mainly caused by the cloud optical thickness. The differences of the CMFs in the five cases include the impact of SZA, COT, cloud vertical distribu- 
tion, and cloud scattering phase matrices, because the other DAK input data are the same for these cases. As shown in Fig. 14, the CMFs are larger than 1 above the cloud top and smaller than 1 below the cloud base. The maximum CMF happens just below the cloud top and decreases almost linearly towards the cloud base. Following Madronich (1987) the features in Fig. 14 can be well understood. The actinic flux above clouds is larger than the clear-sky value because the effective albedo of cloud and surface together is greater than the surface albedo alone. Since the low cloud layers in Figs. 9-13 are all optically thick clouds, the incident light at cloud top cannot easily transmit through the cloud layer. Therefore, the CMFs are smaller than 1 below cloud base. Inside clouds, the peak of CMF happens in a layer below cloud top where the direct incident light is strongly reduced but has given rise to a diffuse downward flux while the lower part of the cloud is still optically thick. In this case the lower part of the clouds creates a high albedo; the top layer of the cloud reflects downward the reflected light again. These components of the diffuse radiation field create a strong enhancement inside the cloud.

\section{Conclusions}

A green light sensor was developed and launched from De Bilt on an ozonesonde balloon between June 2006 and April 2010. Several copies of this sensor were calibrated to one reference sensor to make them intercomparable, although not absolutely calibrated. The calibration failed in 2007; therefore mainly the 2006 data (ascending profiles) were used in the analysis. The instrument is not sensitive to ozone and water vapour, and it is temperature-stabilized. In total there were 63 launches (one ascending profile and one descending profile per launch), of which 9 launches were made during clear-sky conditions. The other launches were made through cloudy atmospheres. The actinic flux profiles contain very little noise, and the impact of clouds on the actinic flux profile could be clearly detected.

The actinic flux profile reveals a large enhancement at the cloud top. Above the cloud top, the actinic flux profile is still influenced by the clouds, but the enhancement is smaller than at the cloud top. The actinic flux profile decreases from the cloud top to cloud base, almost linearly. Below the cloud base, the actinic flux profile is relatively constant, especially for the low clouds. The balloon often passed through several layers of clouds. Therefore, the actinic flux of different heights reflects different cloud conditions along the flight track. The cloud impact is quantified by the cloud modification factor. The CMF is in the range of 1-2.3 at the cloud top and $1-0.1$ at the cloud base. The measurements have demonstrated that the CMF depends on cloud properties and SZA. The measured CMF values agree with the DAK-simulated CMF, especially for cloud base CMF. The CMF at the cloud top is more complicated because sometimes the location of the cloud top can be ambiguous due to the horizontal movement of the balloon in the clouds or due to holes in vertical direction (broken clouds). For the calculation of the clear-sky actinic flux, the same aerosol setting has been used for all cloudy cases, which could cause a small (5\%) uncertainty in the CMF.

The shapes of simulated actinic flux profiles are in good agreement with the actinic flux profile measurements, except for large SZA. This is because the actinic flux profiles have been computed at one wavelength to represent the broadband actinic flux measurements. In principle, the actinic flux profile should be simulated as a spectrum at a fine wavelength grid and then convolved with the spectral response of the instrument. According to our sensitivity analysis on the wavelength dependence of the actinic flux profile, this approximation is valid at small solar zenith angle. So for low sun, it is important to take into account the wavelength dependence of the actinic flux profile.

The actinic flux profiles for single-layer water clouds during fully cloudy conditions were simulated using DAK. The most important input for the simulation is the cloud optical thickness along the flight track, which was obtained from 15 min SEVIRI observations. However, when the optical properties of the clouds are variable at the pixel-to-pixel scale, the SEVIRI COT has to be modified to get a better simulation of the actinic flux profile. In reality, there were mostly multi-layer clouds during the actinic flux profile measurements. Because the SEVIRI cloud optical thickness product provides the total optical thickness of all cloud layers, the optical thickness of the individual cloud layers is unknown in a multi-layer cloud scene. Using multi-layer clouds in the DAK simulation will introduce more free parameters, which may not yield a real closure. We have used the peak of the actinic flux profile to determine the cloud top height used in DAK because, using this specification, DAK reproduces the peak of the measured actinic flux profile at a similar altitude. The cloud top height is very close to the peak of the actinic flux for optically thick clouds over a dark surface, which is mostly the case in our measurements. The ideal option would be to obtain a true cloud top height. The impact of multi-layer cloud structure and 3-D cloud structure remains to be investigated further. Although the clouds have been simplified in the actinic flux profile simulation compared to the clouds in the real measurements, it helps us to understand our instrument and measurements.

For clear-sky conditions, the most important factors determining the shape and magnitude of the actinic flux profiles are SZA, surface albedo, aerosol optical thickness, and aerosol height. Using the aerosol optical thickness data for Cabauw, the measured actinic flux profiles could be simulated reasonably well. The simulations could be improved if we had aerosol data along the flight track of the balloon.

The green light sensor that we used for the actinic flux profile measurements is inexpensive and stable. In combination with a ground-based irradiance measurement and retrieved 
COT from SEVIRI, actinic flux profiles can be calculated. The light sensor is useful for the evaluation of the impact of clouds on actinic flux profiles. Applications of measured actinic flux profiles and simultaneous ozone and $\mathrm{NO}_{2}$ profiles (Sluis et al., 2010) in atmospheric chemistry models will be studied in the future.

Acknowledgements. We would like to thank our colleague M. van Weele (KNMI) for his comments and suggestions about the manuscript. We appreciate J. F. Meirink (KNMI) for his help with the SEVIRI CPP product, available on http://msgcpp.knmi.nl. We acknowledge the MODIS mission scientists and associated NASA personnel for the production of the MODIS AOT data. This research is supported by NWO (Netherlands Organisation for Scientific Research) through the GO project "Cloud radiative forcing profile and vertical energy redistribution in the atmosphere (CRAFT)", project number ALW-GO-AO/09-22.

Edited by: S. Kazadzis

\section{References}

Anderson, G. P., Clough, S. A., Kneizys, F. X., Chetwynd, J. H., and Shettle, E. P.: AFGL atmospheric constituent profiles, Tech. Rep. AFGL-TR-86-0110, Air Force Geophys. Lab., Hanscom AFB, Mass, 1986.

Antón, M., Alados-Arboledas, L., Guerrero-Rascado, J. L., Costa, M. J., C Chiu, J., and Olmo, F. J.: Experimental and modeled UV erythemal irradiance under overcast conditions: the role of cloud optical depth, Atmos. Chem. Phys., 12, 11723-11732, doi:10.5194/acp-12-11723-2012, 2012.

Bodhaine, B. A., Wood, N. B., Dutton, E. G., and Slusser, J. R.: On Rayleigh optical depth calculations, J. Atmos. Ocean. Tech., 16, 1854-1861, doi:10.1175/15200426(1999)016<1854:ORODC>2.0.CO;2, 1999.

Brooks, D. R. and Mims III, F. M.: Development of an inexpensive handheld LED-based Sun photometer for the GLOBE program, J. Geophys. Res., 106, 4733-4740, doi:10.1029/2000JD900545, 2001.

Calbó, J., Pagès, D., and González, J.-A.: Empirical studies of cloud effects on UV radiation: a review, Rev. Geophys., 43, RG2002, doi:10.1029/2004RG000155, 2005.

Cantrell, C. A., Shetter, R. E., Calvert, J. G., Parrish, D. D., Fehsenfeld, F. C., Goldan, P. D., Kuster, W., Williams, E. J., Westberg, H. H., Allwine, G., and Martin, R.: Peroxy radicals as measured in ROSE and estimated from photostationary state deviations, J. Geophys. Res., 98, 18355-18366, doi:10.1029/93JD01794, 1993.

Crawford, J., Shetter, R. E., Lefer, B., Cantrell, C., Junkermann, W., Madronich, S., and Calvert, J.: Clouds and trace gas distributions during TRACE-P, J. Geophys. Res., 108, 8818, doi:10.1029/2002JD003177, 2003.

Crutzen, P. J. and Zimmermann, P. H.: The changing photochemistry of the troposphere, Tellus B, 43, 136-151, doi:10.1034/j.1600-0889.1991.t01-1-00012.x, 1991.
De Haan, J. F., Bosma, P. B., and Hovenier, J. W.: The adding method for multiple scattering computations of polarized light, Astron. Astrophys., 183, 371-391, 1987.

De Roode, S. R., Duynkerke, P. G., Boot, W., and Van der Hage, J. C. H.: Surface and tethered-balloon observations of actinic flux: effects of arctic stratus, surface albedo, and solar zenith angle, J. Geophys. Res., 106, 27497-27507, doi:10.1029/2001JD900236, 2001.

Eskes, H., van Velthoven, P., Valks, P., and Kelder, H.: Assimilation of GOME total ozone satellite observations in a threedimensional tracer transport model, Q. J. Roy. Meteor. Soc., 129, 1663-1681, doi:10.1256/qj.02.14, 2003.

Greuell, W., Meirink, J. F., and Wang, P.: Retrieval and validation of global, direct, and diffuse irradiance derived from SEVIRI satellite observations, J. Geophys. Res.-Atmos., 118, 2340-2361, doi:10.1002/jgrd.50194, 2013.

Hofzumahaus, A., Kraus, A. , Kylling, A., and Zerefos, C.: Solar actinic radiation $(280-420 \mathrm{~nm})$ in the cloud-free troposphere between ground and $12 \mathrm{~km}$ altitude: Measurements and model results, J. Geophys. Res., 107, 8139, doi:10.1029/2001JD900142, 2002 .

Junkermann, W.: Measurements of the $\mathrm{J}\left(\mathrm{O}^{1} \mathrm{D}\right)$ actinic flux within and above stratiform clouds and above snow surfaces, Geophys. Res. Lett., 21, 793-796, doi:10.1029/93GL03498, 1994.

Kazadzis, S., Bais, A. F., Balis, D., Zerefos, C. S., and Blumthaler, M.: Retrieval of downwelling UV actinic flux density spectra from spectral measurements of global and direct solar UV irradiance, J. Geophys. Res., 105, 4857-4864, 2000.

Kylling, A., Albold, A., and Seckmeyer, G.: Transmittance of a cloud is wavelength-dependent in the UV-range: Physical interpretation, Geophys. Res. Lett., 24, 397-400, doi:10.1029/97GL00111, 1997.

Kylling, A., Danielsen, T., Blumthaler, M., Schreder, J., and Johnsen, B.: Twilight tropospheric and stratospheric photodissociation rates derived from balloon borne radiation measurements, Atmos. Chem. Phys., 3, 377-385, doi:10.5194/acp-3-377-2003, 2003.

Kylling, A., Webb, A. R., Kift, R., Gobbi, G. P., Ammannato, L., Barnaba, F., Bais, A., Kazadzis, S., Wendisch, M., Jäkel, E., Schmidt, S., Kniffka, A., Thiel, S., Junkermann, W., Blumthaler, M., Silbernagl, R., Schallhart, B., Schmitt, R., Kjeldstad, B., Thorseth, T. M., Scheirer, R., and Mayer, B.: Spectral actinic flux in the lower troposphere: measurement and 1-D simulations for cloudless, broken cloud and overcast situations, Atmos. Chem. Phys., 5, 1975-1997, doi:10.5194/acp-5-1975-2005, 2005.

Lantz, K. O., Shetter, R. E., Cantrell, C. A., Flocke, S. J., Calvert, J. G., and Madronich, S.: Theoretical, actinometric, and radiometric determinations of the photolysis rate coefficient of $\mathrm{NO}_{2}$ during the Mauna Loa Observatory Photochemistry Experiment 2, J. Geophys. Res., 101, 14613-14630, doi:10.1029/96JD00215, 1996.

Los, A., van Weele, M., and Duynkerke, P. G.: Actinic fluxes in broken cloud fields, J. Geophys. Res., 102, 4257-4266, doi:10.1029/96JD03123, 1997.

Madronich, S.: Photodissociation in the atmosphere 1. Actinic flux and the effect of ground reflections and clouds, J. Geophys. Res., 92, 9740-9752, doi:10.1029/JD092iD08p09740, 1987. 
Mannschreck, K., Gilge, S., Plass-Duelmer, C., Fricke, W., and Berresheim, H.: Assessment of the applicability of $\mathrm{NO}-\mathrm{NO}_{2}-$ $\mathrm{O}_{3}$ photostationary state to long-term measurements at the Hohenpeissenberg GAW Station, Germany, Atmos. Chem. Phys., 4, 1265-1277, doi:10.5194/acp-4-1265-2004, 2004.

Mateos, D., Pace, G., Meloni, D., Bilbao, J., di Sarra, A., de Miguel, A., Casasanta, G., and Min, Q.: Observed influence of liquid cloud microphysical properties on ultraviolet surface radiation, J. Geophys. Res.-Atmos., 119, 2429-2440, doi:10.1002/2013JD020309, 2014.

Mayer, B., Kylling, A., Madronich, S., and Seckmeyer, G.: Enhanced absorption of UV radiation due to multiple scattering in clouds: experimental evidence and theoretical explanation, J. Geophys. Res., 103, 31241-31254, doi:10.1029/98JD02676, 1998.

McKenzie, R. L., Johnston, P. V., Smile, D., Bodhaine, B. A., and Madronich, S.: Altitude effects on UV spectral radiance deduced from measurements at Lauder, New Zealand, and Mauna Loa Observatory, Hawaii, J. Geophys. Res., 106, 22845-22860, doi:10.1029/2001JD900135, 2001.

Palancar, G. G., Shetter, R. E., Hall, S. R., Toselli, B. M., and Madronich, S.: Ultraviolet actinic flux in clear and cloudy atmospheres: model calculations and aircraft-based measurements, Atmos. Chem. Phys., 11, 5457-5469, doi:10.5194/acp-11-54572011, 2011.

Roebeling, R. A., Feijt, A. J., and Stammes, P.: Cloud property retrievals for climate monitoring: implications of differences between Spinning Enhanced Visible and Infrared Imager (SEVIRI) on Meteosat-8 and Advanced Very High Resolution Radiometer (AVHRR) on NOAA-17, J. Geophys. Res., 111, D20210, doi:10.1029/2005JD006990, 2006.

Schiller, C., Hofzumahaus, A., Müller, M., Klein, E., Röth, E.P., and Schmidt, U.: Ultraviolet actinic flux in the stratosphere: An overview of balloon-borne measurements during EASOE, 1991/92, Geophys. Res. Lett., 21, 1239-1242, 1994.
Schwander, H., Koepke, P., Kaifel, A., and Seckmeyer, G.: Modification of spectral UV irradiance by clouds, J. Geophys. Res., 107, 4296, doi:10.1029/2001JD001297, 2002.

Seckmeyer, G., Erb, R., and Albold, A.: Transmittance of a cloud is wavelength-dependent in the UV-range, Geophys. Res. Lett., 23, 2753-2755, 1996.

Sluis, W. W., Allaart, M. A. F., Piters, A. J. M., and Gast, L. F. L.: The development of a nitrogen dioxide sonde, Atmos. Meas. Tech., 3, 1753-1762, doi:10.5194/amt-3-1753-2010, 2010.

Stammes, P.: Spectral radiance modelling in the UV-Visible range, in: IRS 2000: Current Problems in Atmospheric Radiation, edited by: Smith, W. L. and Timofeyev, Y. M., A. Deepak Publ., Hampton, VA, 385-388, 2001.

Stammes, P., de Haan, J. F., and Hovenier, J. W.: The polarized internal radiation field of a planetary atmosphere, Astron. Astrophys., 225, 239-259, 1989.

van Weele, M.: Effect of clouds on ultraviolet radiation, photodissociation rates of chemical species in the troposphere, $\mathrm{PhD}$ thesis, University of Utrecht, Utrecht, the Netherlands, 1996.

van Weele, M., Vilà-Guerau de Arellano, J., and Kuik, F.: Combined measurements of UV-A actinic flux, UV-A irradiance and global radiation in relation to photodissociation rates, Tellus B, 47, 353364, doi:10.1034/j.1600-0889.47.issue3.6.x, 1995.

Vilà-Guerau de Arellano, J., Duynkerke, P. G., and van Weele, M.: Tethered-balloon measurements of actinic flux in a cloudcapped marine boundary layer, J. Geophys. Res., 99, 3699-3705, doi:10.1029/93JD03090, 1994.

Wang, P., Knap, W. H., Kuipers-Munneke, P., and Stammes, P.: Clear-sky shortwave radiative closure for the Cabauw Baseline Surface Radiation Network site, the Netherlands, J. Geophys. Res., 114, D14206, doi:10.1029/2009JD011978, 2009.

Wang, P., Knap, W. H., and Stammes, P.: Cloudy-sky shortwave radiative closure for a Baseline Surface Radiation Network site, J. Geophys. Res., 116, D08202, doi:10.1029/2010JD015141, 2011. 